University of Nebraska - Lincoln

DigitalCommons@University of Nebraska - Lincoln

Faculty Publications, UNL Libraries

Libraries at University of Nebraska-Lincoln

January 1999

Scenario Planning and Collection Development

Joan Giesecke

Universityof Nebraska-Lincoln, jgiesecke1@unl.edu

Follow this and additional works at: https://digitalcommons.unl.edu/libraryscience

Part of the Library and Information Science Commons

Giesecke, Joan, "Scenario Planning and Collection Development" (1999). Faculty Publications, UNL Libraries. 65.

https://digitalcommons.unl.edu/libraryscience/65

This Article is brought to you for free and open access by the Libraries at University of Nebraska-Lincoln at DigitalCommons@University of Nebraska - Lincoln. It has been accepted for inclusion in Faculty Publications, UNL Libraries by an authorized administrator of DigitalCommons@University of Nebraska - Lincoln. 


\title{
Scenario Planning and Collection Development
}

\author{
Joan Giesecke
}

Most of the press these days on the world of information seems to believe that we are all building virtual libraries for virtual students of the virtual university. Reports on the demise of higher education as we know it abound and the latest hope for the future is distance education efforts. Financing higher education is an ongoing crisis with many elected and appointed boards and officials beginning to believe that all will be saved by a telecommunications structure that will somehow free them from having to support higher education. They also believe that somehow information will be free-or as the popular saying goes-Everything you need is on the Internet and it's free. Even the Rand Corporation's Council for Aid to Education, in a report entitled "Breaking the Social Contract" implies that content will be free to the user. To quote from their recommendation on libraries, "Substantial savings and improved library services can be obtained by focusing on the software needed to place library resources on the Internet rather than continuing to support individual research library collections."1 One wonders where these "experts" have been lately. Have they ever seen an invoice for an electronic publication? Do they have any idea that Elsevier exists?

But, for us, the question isn't so much what the experts think, but what kind of future do we envision for ourselves? How do we see the

Joan Giesecke is Dean of Libraries at the University of Nebraska-Lincoln in Lincoln, NE.

[Haworth co-indexing entry note]: "Scenario Planning and Collection Development." Giesecke, Joan. Co-published simultaneously in Journal of Library Administration (The Haworth Information Press, an imprint of The Haworth Press, Inc.) Vol. 28, No. 1, 1999, pp. 81-92; and: Collection Development in a Digital Environment (ed: Sul H. Lee) The Haworth Information Press, an imprint of The Haworth Press, Inc., 1999, pp. 81-92. Single or multiple copies of this article are available for a fee from The Haworth Document Delivery Service [1-800-342-9678, 9:00 a.m. - 5:00 p.m. (EST). E-mail address: getinfo@ haworthpressinc.com].

(c) 1999 by The Haworth Press, Inc. All rights reserved. 
library collection developing over the next 5 to 10 years? How can we predict the future and, more importantly, what if we guess wrong?

In changing times with many uncertainties, managers need planning processes that encourage flexibility and creativity. We can think strategically about the future; we can envision an ideal future. But in the practical, real world of decision-making, we need a system that helps us to both think the unthinkable and plan for multiple options. We can not always guess correctly about the future, so we need to design techniques that let us envision a variety of options and then plan for those possibilities.

One technique that can help managers plan for multiple futures is scenario-driven planning. Scenario planning is a structured, disciplined technique for identifying key driving forces in the environment that have an impact on the organization and then using that information to design a series of scenarios or stories that describe possible futures. Using these stories, managers can design strategies that will help the organization reach its goal under a variety of circumstances. The stories help managers identify their own assumptions about the future and test those assumptions as they review and renew the scenarios.

The result of scenario planning exercise is not an accurate prediction of the future. Rather, the stories provide managers with options to consider and help managers create their own futures. Managers can make better decisions when they have considered, discussed, and imagined a variety of options and not just worst case, best case scenarios.

The classic scenario-driven planning experience is that of the Royal Dutch Shell Corporation. $^{2}$ In the 1970 s Pierce Wack's corporate planning team examined events that might impact the price of oil. They looked at what could cause the price of oil to change after years of stability in the market. They developed two scenarios for the company; one where the price of oil remained the same, and one where the price increased dramatically. The team presented their data and waited for managers to react. Nothing happened. The team then developed a new type of scenario. Instead of just looking at the data and trends, the group wrote stories to include the ramifications of the possible changes in the environment. These stories helped the managers imagine a very different future, and allowed managers to explore how they would react if the price of oil changed. As a consequence of the scenario development and subsequent analysis of the options available 
to the company, Royal Dutch Shell was one of the few companies to react quickly when the unthinkable happened: the 1973 oil crisis.

In this paper I will outline the technique of scenario planning and then provide the results of a mini-scenario-planning process we used at the University of Nebraska-Lincoln to look at collection development and digital information.

\section{SCENARIO PLANNING STEPS}

The practice of scenario development and planning can be broken down into eight basic steps. ${ }^{3}$

\section{Step One: Identify the Focal Issue}

In step one, the manager or planning team identifies the key question to be answered or considered in the process. The issue can be as broad as designing a mission statement and vision for an organization or as narrow as a single issue or question. Agreeing to the focus, though, is a key starting point. Unless the group understands the issue at hand, the group is unlikely to develop useful scenarios for the organization to consider.

\section{Step Two: Key Factors in the Environment}

Here the group lists the key factors in the environment that are relevant to the question at hand. This is the basic analysis of the environment that is a part of most planning processes and techniques and includes identifying strengths, weaknesses, opportunities and threats. The group should also identify economic, social, educational, technological, legal and political trends that affect the focal issue. In looking at collection development, key factors might include publishers' views of the future, budget considerations, inflation rates for library materials, or political changes that will impact what information is available and how that information is available.

\section{Step Three: List the Driving Forces}

In this step the group identifies those forces that will impact the future or are most likely to drive changes in the future. For example, in 
collection development, publisher pricing policies could be a driving force. Another driving force could be changes in user needs as the curriculum changes.

\section{Step Four: Rank the Factors and Trends}

Now the group ranks the factors or driving forces to pick out the most important forces and the most uncertain forces. These two elements-most important and most uncertain-will form the basis for the scenarios.

\section{Step Five: Select the Plot Lines}

The ranking exercise provides the axis for a matrix of possible plot lines. Each factor is placed on a continuum to yield four quadrants or four plot lines. The stories developed from these four options will move the group beyond best case, worst case thinking to considering alternatives that may be plausible in the changing environment.

\section{Step Six: Write the Stories}

Once the issues are identified and the directions of change outlined, the group can develop stories to describe possible futures. The plots need to be complete enough to capture a sense of the changes imagined by the group and simple enough to be usable. If the plots become too complex, decision makers may be lost in details that are not helpful in designing broad strategies. Each plot should have a name that captures the essence of the plot and helps decision makers relate to the story.

\section{Step Seven: Develop the Implications}

Once the stories are in place, the group can outline the implications of the stories. What does each story mean to the organization, to the governing body for the organization, to the front line decision maker? What strategies will be effective in coping with the environment if the scenario proves accurate? What contingencies can be put in place to ensure the greatest chance for the organization to survive? Which strategies are applicable to more than one scenario? How can the organization capitalize on this information to create its own future? 


\section{Step Eight: Selecting the Leading Indicators}

Here the group outlines signposts to watch for to determine if the environment is moving in the direction of one scenario or another. Knowing what to watch for will provide feedback to managers as they decide which sets of strategies to implement as the environment changes. Signposts will help managers know which contingencies to implement, which options to choose, and when a strategy is likely to move the organization in a way that may decrease future flexibility if the manager guesses wrong on a developing trend.

\section{WHEN SCENARIO PLANNING WORKS}

Before embarking on a scenario planning process, managers should consider if the issue or concern is appropriate for a scenario-driven decision-making process. They need to carefully consider what types of uses lend themselves to scenario planning. Ideally, scenario planning works best when:

a. the external environment can evolve in fundamentally different ways. The outcome of these changes is not predetermined.

b. The organization cannot control change.

c. The change is permanent and structural.

d. The organization's actions are dependent upon the way the environment develops.

e. The organization cannot easily redo its decisions after the environment becomes clear. ${ }^{4}$

Scenario planning is a good technique, then, to help an organization address the issues that keep managers up at night.

\section{HOW LONG SHOULD THE PROCESS TAKE}

Scenario planning does require an investment in time by the participants. The entire process from identifying the initial question to be asked to outlining strategies that address the scenarios can take two to three months to complete. Participants need time between each step in the process to reflect on the information developed in the scenario sessions and to consider the implications of future actions. 


\section{DEVELOPING MINI-SCENARIOS}

While the eight-step process for scenario-driven planning is very useful for leading a major planning effort, a simpler approach can be helpful when the problem for analysis is more focused or when time for planning is limited. For organizations that have completed a variety of planning processes and have available environment scans and other planning information, David Mercer suggests a simpler approach to scenario driven planning. Mercer outlines a six-step process for creating mini-scenarios. These steps are:

1. decide the drivers for change

2. bring drivers together into a viable framework

3. produce initial mini-scenarios

4. reduce to two to three scenarios

5. write the scenarios

6. identify the issues arising in the discussions ${ }^{5}$

The simpler approach encourages organizations with planning processes in place to build on the information already gathered in the organization and to use that information in designing scenarios of plausible futures.

For organizations that want to experiment with the process and need to engage participants in new dialogues about outstanding issues, mini-scenario planning sessions can be very effective. In one half-day session, a group that is knowledgeable about the issues and willing to entertain new ideas about the future can outline driving forces, identify key factors and create a matrix of plausible futures. The group can begin to develop the basic outlines of the mini-scenarios and assign someone to complete the story writing assignment. At a second session, the group can review the mini-scenarios and develop a preliminary set of strategies for each of the scenarios. Groups do need time between the two sessions to reflect on the scenarios. They also need time to thoroughly discuss options before outlining strategies and making decisions that could limit future actions of the organization.

\section{POSSIBLE COLLECTION DEVELOPMENT SCENARIOS}

At the University of Nebraska-Lincoln the Collection Development Committee used the simpler process outlined by David Mercer to 
develop four possible scenarios describing possible futures for collection development. The Committee began with the focused question: "How might the collection develop over the next five years?"

To answer that question the group first outlined the key factors or driving forces they saw impacting the libraries and collection development over the next five years. This yielded a list of over 25 items. The committee then grouped similar ideas to create a framework for analyzing change. The grouping of ideas helped the committee members identify overriding factors that could impact the collections in the future.

These groups of issues could yield a number of different and varied scenarios. The committee now had before them major themes that would be incorporated into the final scenarios.

For example, issues such as funding problems were taken as a given while issues predicting the inflation rate of serials were seen as less certain.

From the listing of themes, the group chose the two issues or factors that they saw as most important and most uncertain. The most important factor influencing development of the collection was the needs of the users. The most uncertain factor was the pricing policy of commercial publishers.

The committee developed a matrix based on these two forces (Figure 1). They divided user needs into undergraduate to graduate needs. They divided pricing strategies into monopolistic pricing and affordable pricing. From this matrix, the group identified four scenarios: the One Size Fits All (monopolistic pricing, undergraduate); the Virtual Undergraduate Library (affordable pricing, undergraduate); Researcher Heaven (graduate students, affordable); and Every Researcher on Their Own (monopolistic, graduate) (Figure 2).

The group discussed what they liked and disliked about each possible future as they explored the impact of these scenarios on the collection.

For example, in Every Researcher on Their Own, collection development changes from building collections to navigating the world of information to find non-local resources for researchers. This view of the future impacts many of the core values of collection development librarians in research libraries. The optimism of Researcher Heaven was a delightful contrast to both One Size Fits All and Every Researcher on Their Own. This world of affordable resources offered the collection development librarians the opportunity to look beyond traditional 


\section{FIGURE 1}

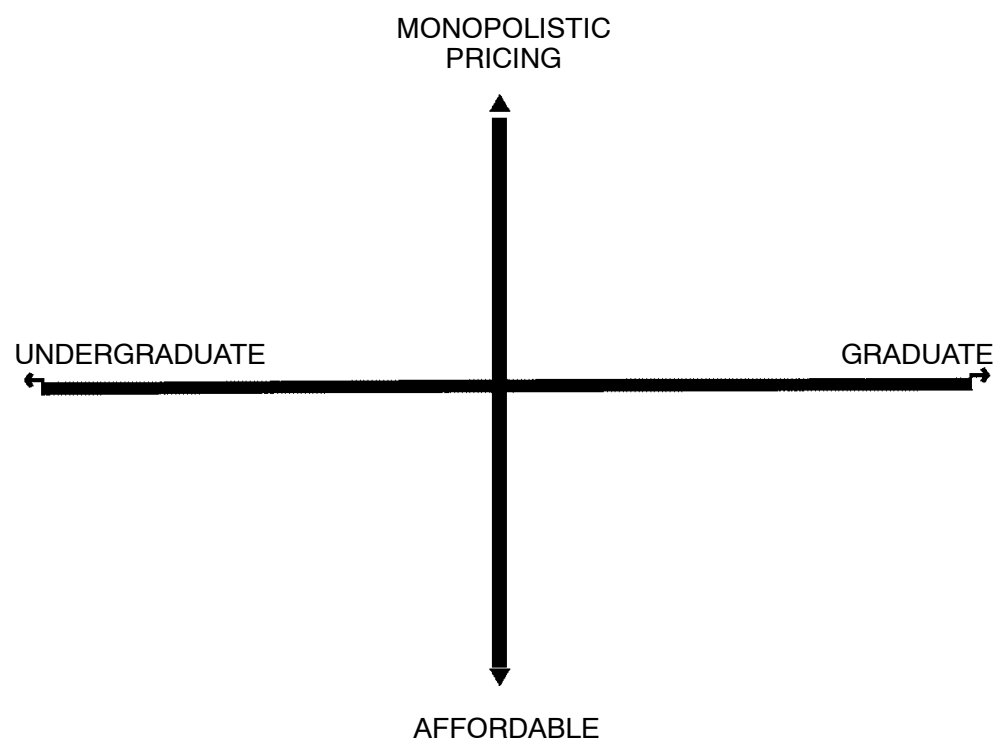

collection efforts to the creation and management of new knowledge. The scenario also raised the very real question of how to provide adequate support for the use of new technologies. The collection development librarians moved from thinking primarily about content to exploring the incorporation of new technologies into their plans.

The group identified strategies that might apply to these scenarios without trying to tie a strategy to a particular story. Strategies listed included: increasing document delivery, purchasing mostly print materials, purchasing mostly electronic material, scanning materials to produce digital archives, increasing hours of user support, purchasing a server for students to use to store their own research files, decreasing serial purchases, and decreasing monograph purchases. The group also looked at strategies to increase access to technology including increasing equipment and computer purchases, providing additional user help for solving computer problems, lobbying for funding for a wireless network, and working with vendors to develop user-friendly 


\section{FIGURE 2}

\section{MONOPOLISTIC}

PRICING

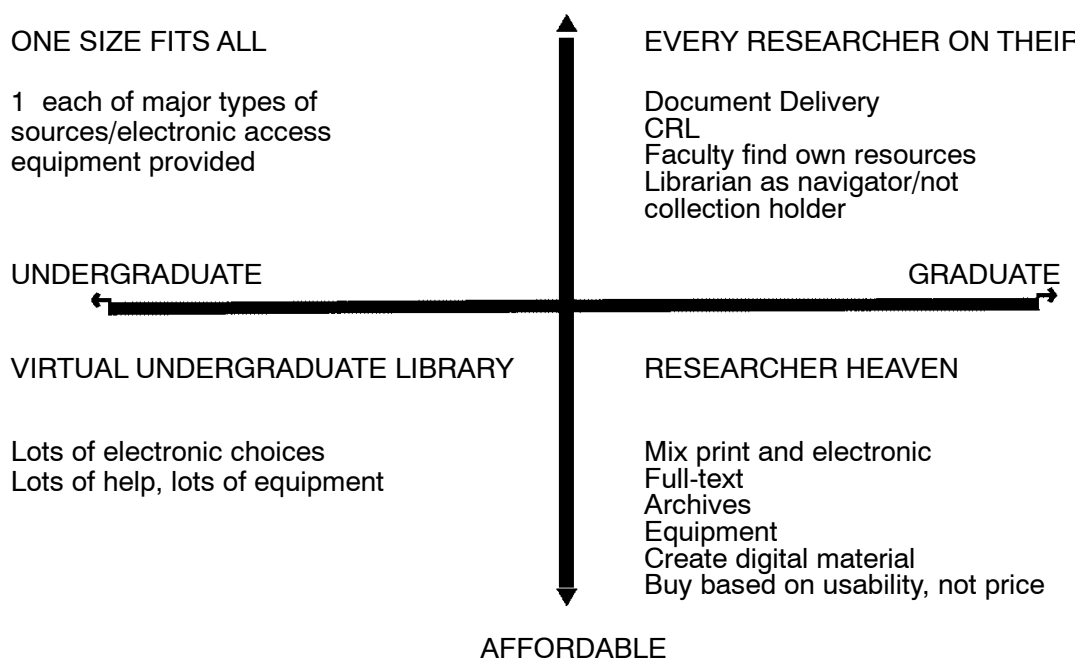

interfaces to electronic products. These strategies address a variety of issues posed by the different scenarios.

The committee is now faced with prioritizing the options to identify those that fit the most number of scenarios. These options are the ones that the library can implement knowing that they will not hurt the library regardless of how the future develops. The committee must then examine those strategies that are more risky, i.e., those that apply to only 1 or 2 scenarios and decide if these strategies are worth the risks they represent.

In this simpler scenario planning process, the group chose to develop only two of the scenarios: the Virtual Undergraduate Library and One Size Fits All (see article Appendix). These scenarios brought life to the concepts the group had discussed and outlined the many issues the group needed to consider in prioritizing strategies.

\section{CONCLUSION}

What strategies should the library field outline to cope with these scenarios? Which current practices can survive if these futures be- 
come reality? Which strategies should we abandon if these scenarios reflect plausible futures?

These are the kinds of questions that face today's collection development librarian and today's managers. How can we prepare for an uncertain future? How can we develop contingencies that provide us with flexibility and keep future options open? We must have the courage to answer these questions, and the energy to explore them if we are to survive as viable institutions in a changing world.

Scenario planning then is not about predicting the future. It is not bound by today's world and it is not limited to thinking the unthinkable. Scenario planning is, however, a structured and disciplined technique that can be used to describe possible futures through carefully developed stories. The futures that are described in the stories are not mutually exclusive, they are not either/or types of plots. They are descriptions of plausible futures that can help managers cope with a variety of environmental changes that may impact their organizations.

\section{NOTES}

1. Council for Aid to Education, Breaking the Social Contract: the Fiscal Crisis in Higher Education (Santa Monica, CA: Rand Corporation, 1997): 22.

2. Joan Giesecke, Scenario Planning for Libraries (Chicago, IL: ALA editions, 1998), forthcoming.

3. Gordon Robbins, "Scenario Planning: A Strategic Alternative," Public Management, 77 (March, 1995): 7.

4. Wally Wood, "Where Do We Go From Here," Across the Board, 34 (March, 1997): 46.

5. David Mercer, "Simpler Scenarios,” Management Decisions, 33 (July, 1995): 35. 


\section{APPENDIX}

\section{Scenario I-One Size Fits All}

Chris and Pat, collection development librarians, were preparing information about the libraries' collections for new students. They were trying to present a positive picture for new students but faced a tough dilemma. They knew the library could afford to provide only a limited range of resources for students. Prices for library materials had become outrageous. Despite increases to the libraries' material budget, they were still unable to add to their limited collection.

Chris and Pat faced a world of monopolistic pricing. A few major firms controlled the publication and production of most of the standard electronic resources. Companies were charging for access to information on the Internet. The era of "free" information was long past.

The faculty had begun to realize the limitations of the libraries' collection and had lowered their expectation for what information students could access outside of the classroom. Nonetheless, students needed access to basic research sources to supplement classroom materials.

The Libraries' collection development policy was focused and limited. The Libraries aimed to serve the basic needs of the undergraduate population. The underlying collection development philosophy was that librarians hoped that one broad-based index or full-text service would cover most needed research. The librarians looked for that one key resource in each major area of the curriculum. The library subscribed to one electronic encyclopedia, one basic full-text journal data base and a few indexes. Other electronic resources became part of a fee-based service where students or faculty paid for access to specialized data bases. Limited print resources were available, although research items had to be obtained through interlibrary loan. Document delivery service was available on a cost recovery basis.

Chris and Pat tried to make the best of this situation. They emphasized that electronic resources were available on the campus network so that students could do much of their research from their dorms. They noted that the library had a leading-edge automated catalog and with links to a variety of resources. Ironically, the library had up-to-date public access work stations for student use as hardware prices had become quite reasonable. For a change, access to equipment was not an issue. Chris and Pat hoped that students would be willing to pay for access to research materials, but realized that most students limited themselves to the few subscriptions that were part of the network. Chris and Pat wondered if students even cared that student access to information resources was limited. 


\section{Scenario II-Virtual Undergraduate Library}

Terry and Sam, collection development librarians, were quite pleased as they prepared materials about the libraries' collection for new students. The library was unveiling its new "Virtual Undergraduate Library Collection." The libraries now provided network access to a wide variety of electronic resources to support undergraduate student research. The publishing market for electronic resources had matured and competition had resulted in affordable products for undergraduate research. The libraries had been in a position to capitalize on these changes and had added a variety of resources to their core holdings. They now could boast of the wonderful global based catalog of indexes, full-text databases, and archival materials available to any member of the campus community.

Equipment issues had also been resolved. Hardware prices had continued to drop and the campus now boasted about its wireless network for students with computers, extensive computer labs, for those without computers, and adequate student help to guide students and faculty through the maze of electronic information available on campus.

Faculty were beginning to recognize how much the library had changed over time and were incorporating electronic resources into their teaching. The faculty knew they could demand more from the students because the library could and did provide access to more resources. Terry and Sam were pleased that they could help contribute to the education process by selecting and adding to the collection resources that could be used by the undergraduate population. 